\title{
Effective Project Control within the Context of Lean Construction
}

\author{
Andre F. Koluksuz \\ fkoluksuz@ashghal.gov.qa \\ Public Works Authority (Ashghal), Doha, Qatar
}

\begin{abstract}
Two of the "Lean Thinking" principles relate to managing a project through relationships, shared knowledge and common goals and to removing waste where possible. Success of a project is only possible with the collaboration of all project participants and stakeholders throughout the entire project life cycle. Collaboration starting at the early stages of the project enables the project participants not only deliver what the owner wants, but also allows them to provide advice and help shape expectations throughout the project. In the age of technology, too much unfiltered data and information are produced quickly, making it a challenge to determine what is significant and what is not. As Project Controls is an important element of "Lean Construction" philosophy, it should be subjected to similar scrutiny to explore opportunities for improvement and for minimizing the waste. This paper will discuss how utilizing both the old and new ideas and methodologies such as the Critical Path Method (CPM), Pareto Principle and Last Planner System ${ }^{\circledR}$ (LPS) will help project managers adopt a balanced approach in selecting the optimal processes, methodologies and tools for meaningful project planning, progress monitoring and communicating the right amount of information on a timely basis.
\end{abstract}

Keywords: Lean thinking; Delay; Pareto principle; Waste

\section{INTRODUCTION}

According to Lean Construction Institute (LCI), currently, $70 \%$ of projects are over budget and delivered late and the results of a recent UK survey indicate that country's 10 biggest contractors made a combined margin of less than half a percent. Evidence from research and observations also indicate that the conceptual models of Construction Management and the tools it utilizes (WBS, Critical Path Method, Earned Value Management) fail to deliver projects 'on-time, at budget, and at desired quality (www. leanconstruction.org ).

Findings of a large scale study on Causes of Cost Overrun in Transport Infrastructure Projects" (Flyvbjerg et al, 2004) and based on a sample of 258 rail, bridge, tunnel and road projects covering 20 nations, state that 9 out of 10 transport infrastructure projects fall victim to cost escalation, average escalation being $28 \%$. It further states that this is a global phenomenon, although cost escalation appears to be more pronounced in developing nations than in North America and Europe. Another striking finding of the study is that cost escalation has not decreased over the past 70 years, clearly showing that no lessons are being learned. 


\section{PROJECT CONTROLS APPROACH}

\subsection{Main Challenges and Causes of Delay}

Lack of "bigger team" spirit, organizational challenges and reluctance to provide honest forecasts and early warnings coupled with dependence on software tools are eroding project managers' ability to utilize judgment and to make sound decisions.

Unrealistic programmes and ineffective controls are being delivered solely to meet contractual requirements rather than being used as a tool for success. Inadequate risk identification and mitigation cause projects to fail or delay due to unforeseen events which are sometimes outside the control of the owner and the contractor.

Results of a study titled "Causes of Delay on Infrastructure Projects in Qatar" (Emam et al., 2015) shows that over $80 \%$ of infrastructure projects suffer from delays with an average delay of $25 \%$ and the top five factors were: long response times from utility agencies; major changes in design during construction; ineffective planning and scheduling; ineffective control of progress, and; changes in the scope of projects. Top ten causes mentioned in this study are tabulated along with main Lean Thinking principles which can be applied to help eliminate these causes (See Table 1).

A similar study titled "Delays in construction projects: A review of causes, need \& scope for further research" based on a wider sample of developing and developed countries, has shown similar factors amongst the top ten causes (Prasad, K and Vasugi, V., 2017).

Table 1 Aligning Lean Principles with Causes of Delay on Infrastructure Projects

\begin{tabular}{|l|l|}
\hline $\begin{array}{l}\text { Cause of Delay (based on Relative Importance } \\
\text { Index, Qatar Study, Emam, H. et al., 2015) }\end{array}$ & $\begin{array}{l}\text { Applicable LEAN Principle \& } \\
\text { Methodologies to help eliminate the } \\
\text { cause of delay }\end{array}$ \\
\hline Long response time from utility agencies & $\begin{array}{l}\text { collaboration, relationship, shared } \\
\text { knowledge }\end{array}$ \\
\hline Major change in design during construction & $\begin{array}{l}\text { shared knowledge, collaboration (early } \\
\text { stakeholder involvement) }\end{array}$ \\
\hline Ineffective planning and scheduling & $\begin{array}{l}\text { LPS (collaboration), minimize waste due to } \\
\text { rework of plans/schedules }\end{array}$ \\
\hline Ineffective control of progress & $\begin{array}{l}\text { LPS (collaboration), minimize waste in } \\
\text { performance measurement and reporting }\end{array}$ \\
\hline Changes in the scope of the project & collaboration, shared knowledge \\
\hline Slow decision-making & $\begin{array}{l}\text { collaboration, relationship, shared } \\
\text { knowledge }\end{array}$ \\
\hline Delay in issuing the drawings & $\begin{array}{l}\text { collaboration, shared knowledge (work } \\
\text { prioritization) }\end{array}$ \\
\hline Delay in solving design problems & $\begin{array}{l}\text { collaboration, shared knowledge (parallel } \\
\text { reviews) }\end{array}$ \\
\hline $\begin{array}{l}\text { Delay in approving shop drawings and sample } \\
\text { materials }\end{array}$ & $\begin{array}{l}\text { collaboration, shared knowledge (parallel } \\
\text { reviews) }\end{array}$ \\
\hline Difficulties in obtaining work permits & collaboration, relationship \\
\hline
\end{tabular}


It is telling that only one of the top ten reasons ("delay in issuing the drawings"), is somewhat related to production and none are related to the constructing activities, where, typically most of the focus in the construction industry has been on many projects. Construction management teams need to adopt project control approaches to tackle the true challenges. Implementing schedule risk management processes by way of producing meaningful plans, schedules and performance indicators will better mitigate the impact of uncertainties and help eliminate the main delay causes listed above.

\subsection{Utilizing Pareto Principle to Reduce Waste in Project Control}

Pareto Principle states that the significant few things will generally make up $80 \%$ of the whole, while the trivial many will make up about $20 \%$. The value of the Pareto Principle is that it helps the project team to focus on what matters the most without entirely ignoring the rest. This can be applied to almost anything;

- $80 \%$ of problems will be caused by $20 \%$ of defects.

- $80 \%$ of project activities are delayed by $20 \%$ of materials.

- $80 \%$ of your results are created in $20 \%$ of your time.

- $80 \%$ of the project information is relayed with $20 \%$ of reports.

- $80 \%$ of delays will be the result of $20 \%$ of the causes.

- $80 \%$ of the desired outcome can be achieved by tackling $20 \%$ of the issues and risks.

To demonstrate how a Pareto Chart can be utilized to identify the significant few focus areas for project management teams, the top 20 causes listed in the above-mentioned study and hypothetical quantitative data are used as an example below (Figure 1).

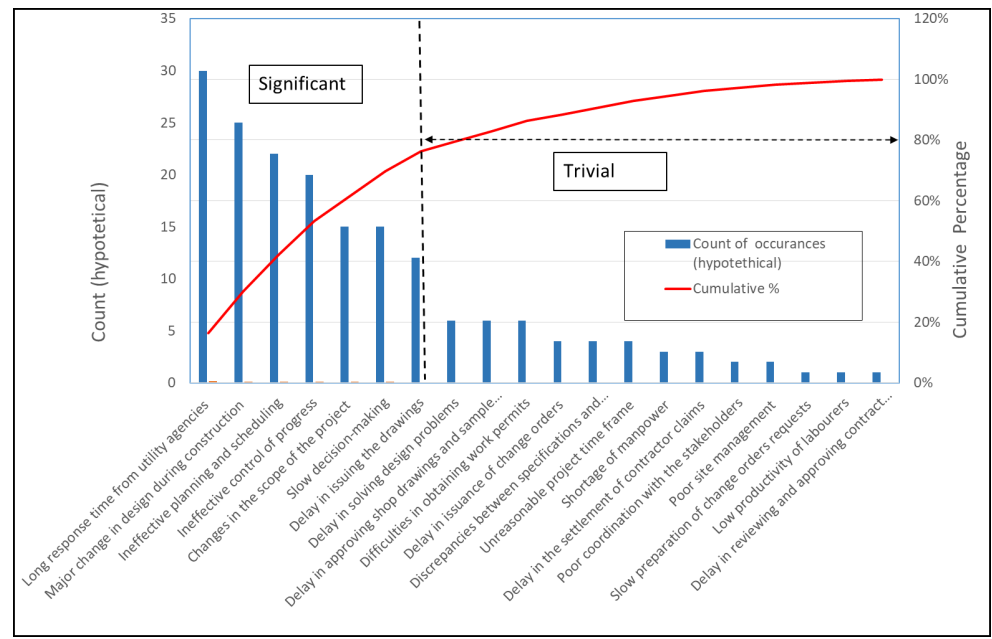

Figure 1: Pareto Chart Example for Delay Causes.

In addition to focusing on the true causes of delay, project management teams should also utilize Lean principles in implementing effective project control processes. These can include manageable size and realistic schedules detailed by phase and developed collaboratively; focusing on the critical and near critical path activities; unbiased and 
realistic cost and time forecasts.

There is generally too much focus on physical works (i.e. constructing) and too little focus on less quantifiable factors, which tend to cause biggest delays. Some of those factors are:

- Unstable design and design interfaces.

- Client and/or stakeholder reviews/permits/approvals.

- Interfaces with other project contractors.

- Authority inspections, certifications.

- Test failures and rework in commissioning stage.

Risks and issues are also good candidates for applying Pareto Principle to. While tackling project risks and issues, it is reasonable to assume that most problems arise from few significant risks and issues. Regular risk reviews for large projects are crucial to identify critical programme activities associated with high risks and determine cost and schedule contingencies to mitigate the risk impact along with other mitigation measures to be put in place by the technical teams.

Last but not least, utilizing software tools for Project and Portfolio Management is another area often overemphasized despite lack of evidence that the projects executed globally in the last 20 years had any better success rates than the projects executed pretechnology age. Those who demand $100 \%$ functionality, $100 \%$ centralized system and $100 \%$ automation will fail $100 \%$.

\subsection{Last Planner System ${ }^{\circledR}$}

The main benefits of Last Planner System (Figure 2) is that the plans are generated with input from all teams to ensure collaboration and buy-in and designed to define clear outcomes and constraints in each phase to ensure reliable commitments. It also reduces wasted effort by project control teams by passing the responsibility of planning and monitoring of daily/weekly tasks to the site teams who are performing the work.

Establishing the main objective of the project, phase pull planning method, identifying and removing the constraints with make-ready planning are important elements of the LPS.

Along with benefits provided, the Last Planner System ${ }^{\circledR}$ has its shortfalls. Last Planner ${ }^{\circledR}$ does not readily provide a platform to analyse criticality and effect of changes to the master plan. When project teams or corporate management need alternate plans, "what-if" schedules are required to quickly demonstrate the effect. This is when the CPM based schedules will provide a complimentary platform to the LPS. While the ratio is not necessarily $80-20$, there is generally smaller core set(s) of tasks, i.e. the "critical and near-critical paths" which are essential to project success. This is where the project teams and the project control staff should focus most of their energy. 




Figure 2: Last Planner System ${ }^{\circledR}$.

\subsection{Programme Performance Indicators and Reporting}

Some of the commonly used schedule performance measurement metrics such as Earned Value, SPI, which can be classified as lagging indicators, have been proven to be misleading and insufficient due to the calculation methods used and its focus on physical construction activities. Using the quantitative SPI without much reference to the schedule floats and criticality of the works can be misleading as it may hide the fact that the right amount of work is being done in the wrong place.

Forward looking (i.e. leading) Key Performance Indicator trends (KPI) such as Variance from baseline dates for Key Milestones, rate of design and material submissions/ approvals/rejections, time taken to obtain permits/approvals, percentage of weekly activities completed, resource assignment against the plan, float erosion would be more meaningful measures of the schedule performance.

On the commercial side, metrics such as turnaround time for payments, claims settlements, variation approvals, tender reviews, and percentage of materials ordered on time would also be better indicators of where the project is heading.

\section{CONCLUSION}

Given all the evidence and historical data, it is clear that incremental improvements and timid action, rather than a bold new approach to project control, will not make a visible difference in project performance. Construction industry has lost decades doing the same thing over and over again and expecting different results. The humble admission that everyone has their share in failure- albeit at different times and on a different scaleis sorely needed.

There is wealth of statistical and lessons learnt data in the Middle East in general and Qatar in particular thanks to the large number of megaprojects of all kinds having been completed since the awarding of FIFA World Cup to Qatar. This will provide a tremendous opportunity to all the project managers in the region and worldwide to evaluate the best practices in construction management in search of successful project execution.

Foundations of and fundamental thinking behind the Critical Path Method, Pareto 
Principle and Lean Construction will help the construction industry immensely in achieving better project performance. Identifying the problems correctly and focusing efforts on the most significant challenges will enable the project control professionals to add more value and will create a positive working environment for all stakeholders and individuals towards the common goal.

\section{REFERENCES}

Emam, H., Farrell, P. \& Abdelaal, M. (2015). Causes of delay on infrastructure projects in Qatar.

Flyvbjerg, B., Skamris Holm, M. \& Buhl, S. (2004). What Causes Cost Overrun in Transport Infrastructure Projects. Transport Reviews, Vol. 24, No. 1, pp. 3-18.

Prasad, K. \& Vasugi, V. (2017). Delays in construction projects: A review of causes, need \& scope for further research. Malaysian Construction Research Journal, Vol. 23, No. 3, pp.89-113. 